\title{
PHENOLSULPHONEPHTHALEIN ABSORPTION FROM THE SUBARACHNOID SPACE IN PARESIS AND DEMENTIA PRAECOX
}

\author{
PAUL G. WESTON, M.D. \\ WARREN, PA.
}

The study of absorption of dye from the subarachnoid space is not new. The use of phenolsulphonephthalein is, however, of comparatively recent origin. Dandy and Blackfan ${ }^{1}$ used it in their studies of hydrocephalus. (The solution used was neutral in reaction and nontoxic. The solution prepared for kidney function tests should not be used because of its alkaline reaction.) In thirty to fifty minutes after the dye had been injected into the subarachnoid space, traces of it were found in the right lymphatic and thoracic ducts whereas the dye appeared in the blood in three and in the urine in six minutes. In two hours from 35 to 60 per cent. of the dye was recovered in the urine. They conclude that the cerebrospinal fluid passes directly into the blood, and the lymph spaces are not concerned with its absorption. Shortly after the dye had been injected into the lumbar subarachnoid space, it was found in the cerebral ven. tricles.

Mehrtens and West ${ }^{2}$ used phenolsulphonephthalein in a series of cases and reported their results in 1917. They injected 1 c.c. of the neutral dye into the lumbar subarachnoid space, washed the dye from the needle with 3 c.c. of previously withdrawn spinal fluid, thus preventing its escape into the muscles along the needle track when the needle was withdrawn; they catheterized the bladder and determined the time of appearance of the dye in the urine. Quantitative estimations of the amount excreted varied greatly, and the authors suggest that the dye may suffer considerable reduction before complete elimination can take place. Some of the spinal fluids showed a reduction of from 10 to 20 per cent., while others showed no reduction at all. They observed that diseases of the central nervous system, especially when involving the meninges, produce a lengthening of the appearance time to as much as sevently minutes in some cases. In syphilis a lengthening of the appearance time may be produced before any other evidence of central nervous system involvement has appeared, and they conclude that at present no definite conclusion can be drawn as to the exact location of the absorbing tissue.

1. Dandy, W. E., and Blackfan, K. D.: An Experimental and Clinical Study of Internal Hydrocephalus, J. A. M. A. 61:2216 (Dec. 20) 1913.

2. Mehrtens, H. G., and West, H. F.: Arch. Int Med. 20:575 (Oct.) 1917. 
Incidental to the routine examination of the spinal fluid in a number of cases of paresis and catatonic dementia praecox, observations were made by the writer on the absorption of the phenolsulphonephthalein from the subarachnoid space.

TECHNIC

Patients were placed on their left side with the buttocks and shoulders on the same level. The skin was cocainized; lumbar punctures made between the third and fourth lumbar vertebrae and a stopcock connected with the needle. Three c.c. of fluid were collected under sterilized paraffin oil for the determination of specific gravity, hydrogen-ion concentration, colloidal gold and globulin tests and the Wassermann reaction. A rubber tube $5 \mathrm{~cm}$. in length with adapters and connected with a 30 c.c. Luer syringe barrel was then attached to the stopcock, and 15 c.c. of spinal fluid were allowed to flow into the syringe barrel. The rubber tube was closed by kinking it on itself and then detaching it. A 2 c.c. tuberculin syringe containing 1 c.c. of a sterilized, neutral solution of phenolsulphonephthalein having a specific gravity of 1.0061 was connected with the stopcock and the dye slowly injected. The syringe was disconnected and the rubber tubing leading from the 30 c.c. syringe was attached to the stopcock. The 15 c.c. of previously withdrawn spinal fluid were slowly injected by controlling the pressure on the piston so that two minutes were required to empty the syringe. In this way the dye was thoroughly washed from the needle. Immediately after the needle was withdrawn the patient was placed on his back, the bladder catheterized and the time of appearance of the dye determined by collecting the urine in a test tube containing a few drops of 10 per cent. sodium hydrate solution.

Three or more days after the intraspinal injection, the bladder was catheterized and as soon as it was empty, 1 c.c. of the neutralized dye was injected deep into the deltoid muscle and the time of its appearance in the urine determined. The stopcock made it possible to withdraw fluid and inject the dye without losing a drop of either.

\section{DISTRIBUTION OF THE DYE}

It was necessary first to determine the average amount of cerebrospinal fluid in cases of dementia praecox and paresis. Such information was obtained from cadavers. Immediately after death, with the body on its back and the head slightly elevated, a needle was inserted into the cisterna magna and another into the lateral ventricle, a small hole having been bored through the skull for the purpose. The fluid was collected in a graduated cylinder and the head rotated 
several times until no more fluid flowed from the cisterna. The body was then turned on its side with shoulders slightly elevated and a needle inserted between the twelfth thoracic and first lumbar vertebrae. The fluid flowing from this needle and representing the amount in the canal from the medulla to the end of the cord was collected and measured. When no more fluid flowed, a fourth needle was inserted between the last lumbar and first sacral vertebrae. Fluid flowing from this needle represented the amount in the lumbar area. The average amount of fluid in sixty dementia praecox cases of all forms was 110 c.c. in the skull, 15 c.c. in the thoracic part of the cord and 15 c.c. in the lumbar area. From twenty-eight cases of paresis the amounts were 135,18 and 15 c.c., respectively.

TABle 1.-Maximum and Minimum Amounts of Fluid Found

\begin{tabular}{|c|c|c|c|c|c|c|}
\hline & \multicolumn{3}{|c|}{ Maximum Amount in C.e. } & \multicolumn{3}{|c|}{ Minimum Amount in C.c. } \\
\hline & Skull & $\begin{array}{l}\text { Thoracic } \\
\text { Part of Cord }\end{array}$ & $\begin{array}{c}\text { Lumber } \\
\text { Area }\end{array}$ & Skull & $\begin{array}{l}\text { Thoracic } \\
\text { Part of Cord }\end{array}$ & $\underset{\text { Area }}{\text { Lumber }}$ \\
\hline $\begin{array}{l}\text { Dementia praecox } \\
\text { Paresis............ }\end{array}$ & $\begin{array}{l}120 \\
150\end{array}$ & $\begin{array}{l}18 \\
19\end{array}$ & $\begin{array}{l}18 \\
19\end{array}$ & $\begin{array}{r}90 \\
110\end{array}$ & $\begin{array}{l}13 \\
13\end{array}$ & $\begin{array}{l}12 \\
13\end{array}$ \\
\hline
\end{tabular}

The specific gravity of the fluid from the cases observed (determined by pyknometer) varied from 1.0061 to 1.0063 in the dementia praecox group and from 1.0061 to 1.0073 in the paretic group. The specific gravity of the dye was 1.0061 . One would therefore expect the dye to diffuse slowly in those cases in which the specific gravity of the fluid was the same as that of the dye solution and to rise to the higher portions of the cord when the dye solution was lighter than the spinal fluid.

A. E. Barker ${ }^{3}$ studied frozen sections of cadavers and found that with the body on its back, the highest point in the spinal canal was in the cervical region and next to this, the space between the third and fourth lumbar vertebrae. The canal slopes in both directions from this interspace. The cephalic slope continues downward to the fifth and sixth thoracic vertebrae when it begins to run upward again until the third cervical vertebra, or if the head is on a pillow, until the foramen magnum is reached. It would, therefore, seem that the most appropriate place to inject the dye would be between the third and fourth lumbar vertebrae, for this would give it an opportunity to flow in both directions and cause greater diffusion. One would expect to find the dye as far up as the fifth or sixth thoracic vertebrae in a few minutes. Dandy and Blackfan state that the dye finds its way into the cerebral ventricles a few minutes after it is injected into the lumbar subarachnoid space.

3. Barker, A. E.: Brit. M. J. 1:597, 1912. 
In order to determine how far the dye diffused, 1 c.c. was injected as described above into the lumbar subarachnoid space of a cadaver immediately after death. Ten minutes later the cisterna magna was punctured, the buttocks elevated so that the spinal canal was at an angle of about 45 degrees, and 20 c.c. of clear fluid withdrawn before any dye appeared. In another instance puncture between the fifth and sixth thoracic vertebrae with the body placed horizontally yielded clear fluid-no dye was present. These experiments were repeated on other cadavers one hour after injection of the dye, with the same results. The conclusion is that the dye does not leave the lumbar area in cadavers. In a selected number of dementia praecox and paretic cases puncture of the cisterna magna, after injection of the dye into the lumbar subarachnoid space, yielded clear fluid free from traces of color. Punctures were made, one in each case, at intervals of one-fourth, one-half, one, three and five hours after the injection of the dye. In these cases there was no diffusion upward of the dye as far as the cisterna. It, therefore, remained in the lumbar or thoracic regions or was destroyed or absorbed before it could reach the cervical region.

To determine whether the cerebrospinal fluid destroyed the dye, its effects were studied in the test tube. Because of the above findings, it was assumed that all the unabsorbed dye was in the lumbar and lower thoracic regions, and, since there was an average of 20 c.c. of fluid in these areas ( 15 c.c. in the lumbar area plus one-third of the amount in the whole thoracic area), each cubic centimeter contained approximately one-twentieth c.c. of the dye. This amount of dye was then added to 1 c.c. of freshly drawn fluid collected under sterilized paraffin oil and the same amount was added to 1 c.c. of sodium carbonate solution having a $p_{\mathrm{H}}$ of 7.4 , which was the same as that of the spinal fluid. The tubes were covered with sterilized paraffin oil, closed with cork stoppers and placed in the dark at $37 \mathrm{C}$. for twenty-four hours. At the end of this time one-twentieth c.c. of the dye was added to a freshly prepared sodium carbonate solution having a $p_{\mathrm{H}}$ of 7.4. Two c.c. of 5 per cent. sodium hydrate solution were then added to each tube and their contents compared in the Kober colorimeter. The freshly prepared sodium carbonate solution was used as the standard. There was no determinable destruction of the dye by the spinal fluid in any instance. Mehrtens and West ${ }^{2}$ found a reduction of 10 to 20 per cent. in some cases and no reduction at all in others.

The dye was therefore not reduced by the fluid in a test tube under the above conditions and perhaps was not reduced by it in the spinal canal. Quantitative estimations of the amount of dye elimi- 
nated were not made. The observations that have been made indicate that the dye is absorbed from the lumbar region and that it does not reach the cisterna in five hours.

\section{APPEARANCE TIME}

Dandy and Blackfan found the dye in the urine six minutes after it had been injected into the lumbar subarachnoid space. The tables in the paper of Mehrtens and West give the appearance time as four to ten minutes-in one case fourteen minutes. These figures, of course, are for normal subjects or at least for subjects not having demonstrable involvement of the central nervous system.

table 2.-Dementia Praecox Cases

\begin{tabular}{|c|c|c|c|c|}
\hline \multirow{2}{*}{ Number } & \multirow{2}{*}{ Age } & \multirow{2}{*}{ Duration, Years } & \multicolumn{2}{|c|}{ Appearance Time, Minutes } \\
\hline & & & Intraspinal & Intramuscular \\
\hline $\begin{array}{r}9985 \\
5992 \\
6068 \\
8529 \\
8278 \\
8477 \\
4000 \\
5648 \\
8672 \\
5220 \\
10131 \\
7938 \\
6209 \\
6386 \\
6900 \\
8229 \\
6043 \\
7331 \\
9659 \\
9056 \\
8916 \\
5145 \\
8622 \\
5975 \\
7516 \\
5945 \\
7903 \\
10564\end{array}$ & $\begin{array}{l}30 \\
44 \\
34 \\
27 \\
29 \\
34 \\
51 \\
38 \\
27 \\
44 \\
27 \\
35 \\
37 \\
39 \\
30 \\
28 \\
33 \\
34 \\
26 \\
26 \\
28 \\
42 \\
24 \\
33 \\
30 \\
33 \\
30 \\
19\end{array}$ & $\begin{array}{r}6 \\
13 \\
15 \\
6 \\
7 \\
10 \\
25 \\
15 \\
7 \\
20 \\
3 \\
15 \\
19 \\
20 \\
11 \\
8 \\
5 \\
12 \\
3 \\
5 \\
5 \\
16 \\
6 \\
13 \\
10 \\
14 \\
10 \\
1\end{array}$ & $\begin{array}{r}25 \\
25 \\
28 \\
30 \\
30 \\
30 \\
30 \\
35 \\
37 \\
37 \\
37 \\
40 \\
41 \\
42 \\
45 \\
45 \\
48 \\
50 \\
53 \\
55 \\
58 \\
60 \\
65 \\
80 \\
90 \\
96 \\
100 \\
104\end{array}$ & $\begin{array}{r}15 \\
12 \\
13 \\
20 \\
11 \\
15 \\
10 \\
6 \\
18 \\
10 \\
12 \\
7 \\
10 \\
7 \\
4 \\
11 \\
6 \\
10 \\
9 \\
13 \\
10 \\
11 \\
17 \\
11 \\
7 \\
10 \\
8 \\
10\end{array}$ \\
\hline \multicolumn{5}{|c|}{ PARESIS CASES } \\
\hline $\begin{array}{r}10150 \\
10719 \\
10675 \\
10716 \\
8316 \\
10189 \\
10503 \\
10525 \\
10647 \\
9550 \\
10621 \\
10689 \\
8298 \\
10724 \\
10854 \\
10085 \\
10414\end{array}$ & $\begin{array}{l}37 \\
34 \\
83 \\
46 \\
38 \\
84 \\
54 \\
39 \\
39 \\
39 \\
49 \\
39 \\
43 \\
47 \\
52 \\
31 \\
40\end{array}$ & $\begin{array}{l}4 \\
1 \\
3 \\
2 \\
4 \\
2 \\
1 \\
2 \\
2 \\
5 \\
1 \\
1 \\
7 \\
2 \\
2 \\
3 \\
4\end{array}$ & $\begin{array}{l}12 \\
13 \\
25 \\
25 \\
26 \\
28 \\
28 \\
30 \\
31 \\
32 \\
33 \\
34 \\
35 \\
40 \\
42 \\
51 \\
68\end{array}$ & $\begin{array}{r}18 \\
9 \\
15 \\
10 \\
14 \\
18 \\
19 \\
14 \\
10 \\
12 \\
20 \\
12 \\
14 \\
10 \\
12 \\
17 \\
9\end{array}$ \\
\hline
\end{tabular}


From the table it will be seen that the shortest appearance time in the series was twelve minutes. It occurred in a case of paresis. The longest appearance time was in a case of catatonia, 104 minutes. In the paretic cases the time varied from twelve to sixty-eight minutes and in the dementia praecox group from twenty-five to 104 minutes. After intramuscular injection, the appearance time varied from four to twenty minutes.

\section{SUM MARY}

One c.c. of neutral, sterilized solution of phenolsulphonephthalein having a specific gravity of 1.0061 was injected into the lumbar subarachnoid space and the contents of the needle washed into the canal with 15 c.c. of previously withdrawn spinal fluid. The time of appearance of the dye in the urine was then determined. Twenty-eight cases of catatonic dementia praecox and seventeen cases of paresis were observed. Age, duration of the psychosis, physical and mental condition, so far as could be determined, had no constant effect on the appearance time. In all cases the dye was longer in making its appearance in the urine than the normal time stated by Dandy and Blackfan, six minutes, and by Mehrtens and West, four to ten minutes. In these observations the time varied from twelve to sixty-eight minutes in the case of paresis and from twenty-five to 104 minutes in the case of catatonic dementia praecox.

The specific gravity of the spinal fluid varied from 1.0061 to 1.0063 in the dementia praecox group and from 1.0061 to 1.0073 in the paretic group. The hydrogen-ion concentration in all cases was 7.4. The Wassermann reaction, gold and globulin tests were all negative in the dementia praecox cases and were positive in the paretics.

The dye was not found in fluid drawn from the cisterna magna at any time up to five hours after it had been injected into the lumbar subarachnoid space. The absorption of the dye took place from the lumbar region. 